\title{
What Types of Small and Medium-Sized Businesses are Utilizing New Financial Products?*
}

\author{
Nobuyoshi YAMORI \\ Graduate School of Economics, Nagoya University, Chikusa-ku, Nagoya, Aichi, Japan. \\ Email: yamori@soec.nagoya-u.ac.jp
}

Received September 25, 2009; revised October 31, 2009; accepted December 1, 2009.

\begin{abstract}
The increased diversification of fund rising methods among small and medium-sized businesses has been a major policy challenge in recent years, and private financial institutions are proactively striving to disseminate new financial technologies. However, this does not necessarily mean that every small and medium-sized business benefits from such technologies. It is difficult to analyze this aspect based on ready-made data. Fortunately, this paper can analyze the current status and challenges of the utilization of new financial products among small and medium-sized businesses by using unique survey questionnaires (Kansai RIETI Questionnaires). The results of responses from more than 2,000 companies showed that most companies began utilizing new financial products due to introductions by main banks, and it was seen that the diversification of fund rising methods among small and medium-sized businesses has developed as a result of efforts made by policy-making authorities and financial institutions. However, the rate of utilization of each financial method is as low as a few percentage points, and extremely small businesses or cash-strapped companies has not improved in terms of fund risings. Improved diversification was mainly found in excellent small and medium-sized businesses.
\end{abstract}

Keywords: Financing Products, SME Finance, Relationship Banking, Main Bank

\section{Introduction}

The increased diversification of fund rising methods among small and medium-sized businesses has been a major policy challenge in recent years. According to the "Status of Progress of the Action Program for the Promotion of Functional Enhancement of Community-Based Finance" published by the Financial Service Agency, private financial institutions have been making effort in the areas of 1) financing methods such as intellectual property-collateralized loans focusing on business values, loan-collateralizing movables or transfer of receivables, nonrecourse loans (loans for which the nonexempt property of performance obligation is limited to those subject to financing), or project finance loans; and 2) securitization such as the issuance of asset-backed securities utilizing local CLO (Collateralized Loan Obligation) or accounts receivable held by small and medium-sized businesses. Generally speaking, substantial achievements have generally been obtained.

\footnotetext{
"The author appreciates a financial support provided by the Grant-inAid for Scientific Research (KAKENHI).
}

However, such efforts are not necessarily equally effective for every small and medium-sized business, and currently, many are still suffering amidst the severe financial environment. Therefore, in order to enable the utilization/dissemination of new financial products to lead toward a real facilitation of financing for small and medium-sized businesses, consideration of what may further be required must be sought. Because it is difficult to analyze such aspects with ordinary data, more detailed corporate data such as questionnaires is necessary. Now, in this paper, the current status and challenges of utilizing new financial products among small and mediumsized businesses are analyzed using survey questionnaires (Kansai RIETI Questionnaires) that the RIETI has implemented.

\section{Kansai RIETI Questionnaires}

\subsection{Summary of Questionnaires}

I implemented a survey called "Corporate awareness survey regarding corporate financing in the Kansai Region” in June 2005 as collaborative research with the 
Table 1. Utilization of diversified fund procurement methods

\begin{tabular}{|c|c|c|c|c|c|c|c|c|c|c|c|c|c|c|c|}
\hline 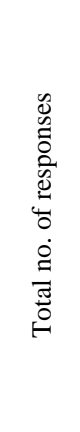 & 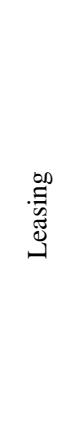 & 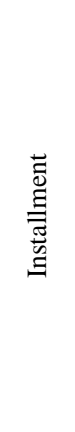 & 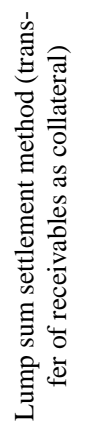 & 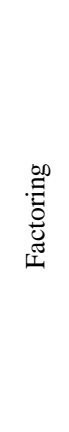 & 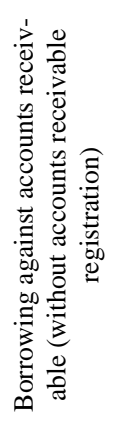 & 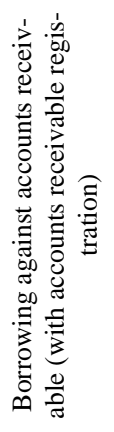 & 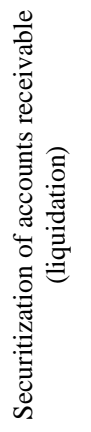 & 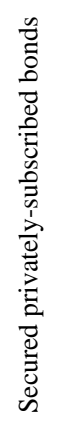 & 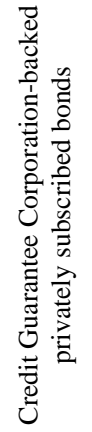 & 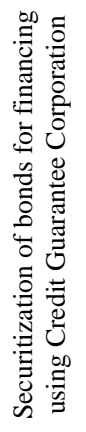 & 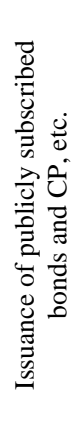 & 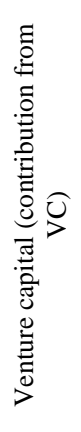 & 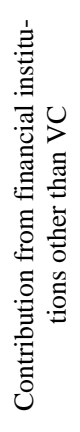 & 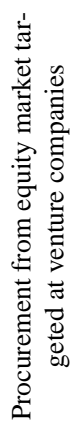 & 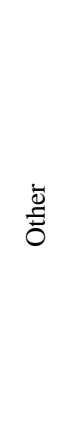 \\
\hline 1129 & 710 & 127 & 55 & 211 & 28 & 9 & 29 & 62 & 121 & 21 & 24 & 1 & 1 & 2 & 157 \\
\hline $100 \%$ & 62.9 & 11.2 & 4.9 & 18.7 & 2.5 & 0.8 & 2.6 & 5.5 & 10.7 & 1.9 & 2.1 & 0.6 & 0.6 & 0.2 & 13.9 \\
\hline
\end{tabular}

Local Financing Study Group (General manager of the project: Professor Yoshiro Tsutsui, Osaka University) of the Research Institute of Economy, Trade and Industry (RIETI). Survey sheets were sent to 9,000 companies with headquarters located in Osaka, Hyogo, and Kyoto prefectures $^{1}$. Survey sheets were mailed out on June 6, 2005, and the 2,041 companies from which we received responses (return rate: $22.68 \%$ ) became subjects in the analysis. However, the actual number of companies that responded varied per questionnaire.

The survey sheets that were mailed to the companies consisted of 54 questions. The questions were divided into eight major sections. Part 1 is the attribution of questionnaire respondents. Part 2 is the attribution of respondent companies. Part 3 consists of questions regarding the general management of respondent companies. General management policies are queried in Part 4, while the relationship with main banks is asked about in Part 5. Part 6 deals with questions regarding general bank transactions. Part 7 consists of questions on how small and medium-sized businesses evaluate financial institutions in terms of loan screening and borrowers monitoring, and Part 8 deals with questions regarding the public creditguarantee system.

\subsection{Current Status of Utilization of New Financial Products and Corporate Size}

In the RIETI Questionnaire, current utilization of various fund procurement methods were asked as shown in Table 1 (Question 19). According to those questions, leasing

${ }^{1}$ For a detailed explanation, refer to Yamori [1]. Yamori [2], Uchida, Udell, and Yamori $[3,4]$ wrote a series of papers based on this Kansai RIETI Questionnaire.

${ }^{2}$ For example, regarding "Procurement utilizing Accounts Receivable," some companies use both "lump sum settlement method" and "factoring."

${ }^{3}$ It is understood that the utilization rate of privately subscribed bonds is low for companies in the largest group because they tend to issue publicly subscribed bonds. showed an outstanding utilization rate, and $62.9 \%$ of the respondent companies utilized leases. Factoring, installment, and Credit Guarantee Corporation-backed privately subscribed bonds follow in this order, and it is clear that fund procurement from non-bank institutions plays a certain significant role. However, such financial methods are not discussed in this paper, in order to facilitate a greater focus on the fund-providing functions of banking institutions.

The five items from the lump sum settlement method (transfer of accounts receivable as collateral) to the securitization of account receivables (liquidation) in Table 1 are, in a broad sense, fund procurement methods utilizing accounts receivable (hereinafter referred to as "Procurement utilizing Accounts Receivable”). Furthermore, secured privately subscribed bonds and Credit Guarantee Corporation-backed privately subscribed bonds are fund procurement by privately subscribed bonds. Then, we investigate how this "Procurement utilizing Accounts Receivable" and "Fund Procurement by Privately Subscribed Bonds" have been utilized and by what types of companies. Since some companies utilize multiple methods ${ }^{2}$, excluding duplications, 287 companies have experience with Procurement utilizing Accounts Receivable, while 179 companies have experience in utilizing privately subscribed bonds.

First, respondent companies were divided into ten groups, depending on the corporate size as determined by the number of employees, and the utilization rate of Procurement utilizing Accounts Receivable and "Fund Procurement by Privately Subscribed Bonds" were calculated for graphic description (Figure 1). With regard to privately subscribed bonds, the effect of size is significantly clear. In other words, there is a tendency in which the larger a company is, the higher will be the utilization rate, excluding the largest companies (210 or more employees) $)^{3}$.

On the other hand, with regard to the utilization rate of 


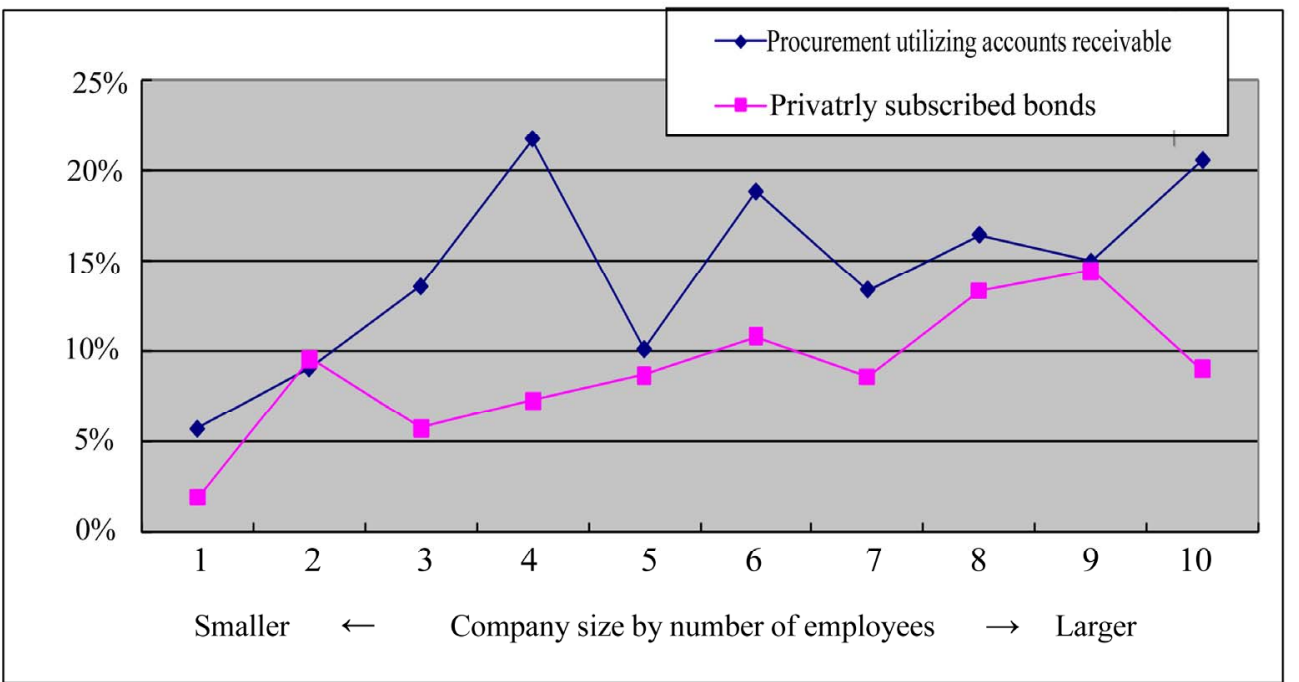

Note: Employee size $1=8$ or less, Size $2=22$ or less, Size $3=30$ or less, Size $4=40$ or less, Size $5=56$ or less, Size $6=70$ or less, Size $7=90$ or less, Size $8=127$ or less, Size $9=210$ or less, and Size $10=211$ or more. The number of companies belong to each group is about 200

Figure 1. Corporate size and utilization rates of fund procurement methods

Table 2. Status of utilization of new financial products

\begin{tabular}{|l|c|c|c|c|c|}
\hline & $\begin{array}{c}\text { Total no. of } \\
\text { responses }\end{array}$ & $\begin{array}{c}\text { Small-group privately } \\
\text { subscribed bonds }\end{array}$ & $\begin{array}{c}\text { Loan guarantee scheme } \\
\text { by accounts receivable }\end{array}$ & CLO & $\begin{array}{c}\text { Quick } \\
\text { loans }\end{array}$ \\
\hline Aware of them & 961 & 590 & 692 & 275 & 427 \\
\hline $\begin{array}{l}\text { Utilized within the last 3 } \\
\text { years }\end{array}$ & 230 & 85 & 29 & 99 & 46 \\
\hline $\begin{array}{l}\text { Introduction by a main bank } \\
\text { was the trigger for utilization }\end{array}$ & 198 & 76 & 34 & 83 & 36 \\
\hline
\end{tabular}

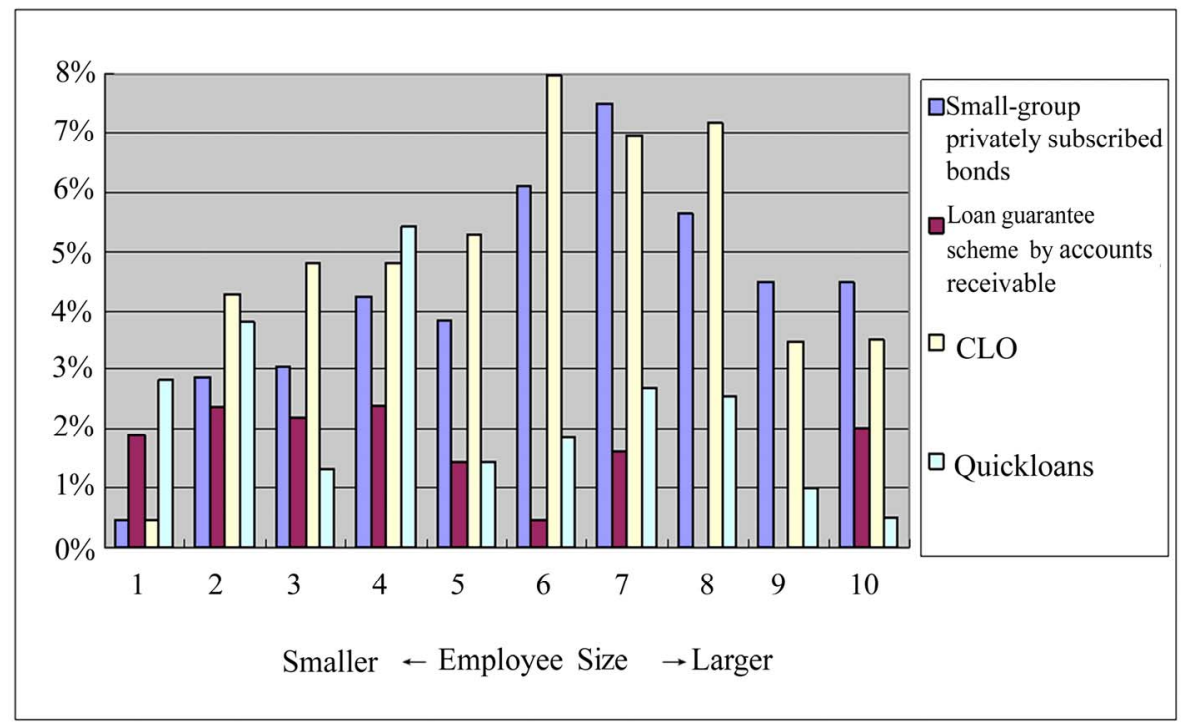

Figure 2. Employee size and status of utilization of new financial products 
Table 3. Utilization rates of new financial products by small and medium-sized businesses and type of operation of main banks

\begin{tabular}{|c|c|c|c|c|}
\hline & Employee size & City bank & $\begin{array}{c}\text { Regional/second-tier regional } \\
\text { bank }\end{array}$ & $\begin{array}{l}\text { credit association (Shinkin } \\
\text { Bank) }\end{array}$ \\
\hline \multirow{3}{*}{$\begin{array}{l}\text { Small-group privately subscribed } \\
\text { bonds }\end{array}$} & 22 or less & $2.8 \%$ & $1.0 \%$ & $1.0 \%$ \\
\hline & 40 or less & $5.6 \%$ & $1.5 \%$ & $0.0 \%$ \\
\hline & Overall & $5.7 \%$ & $2.7 \%$ & $2.3 \%$ \\
\hline \multirow{3}{*}{$\begin{array}{l}\text { Loan guarantee scheme by accounts } \\
\text { receivable }\end{array}$} & 22 or less & $1.4 \%$ & $2.1 \%$ & $3.9 \%$ \\
\hline & 40 or less & $1.0 \%$ & $3.0 \%$ & $6.3 \%$ \\
\hline & Overall & $0.8 \%$ & $2.1 \%$ & $3.5 \%$ \\
\hline \multirow{3}{*}{ CLO } & 22 or less & $4.8 \%$ & $2.1 \%$ & $1.0 \%$ \\
\hline & 40 or less & $7.1 \%$ & $3.0 \%$ & $3.1 \%$ \\
\hline & Overall & $7.2 \%$ & $2.4 \%$ & $2.3 \%$ \\
\hline \multirow{3}{*}{ Quick loan } & 22 or less & $2.8 \%$ & $3.1 \%$ & $6.9 \%$ \\
\hline & 40 or less & $2.5 \%$ & $6.0 \%$ & $1.6 \%$ \\
\hline & Overall & $1.5 \%$ & $3.0 \%$ & $4.2 \%$ \\
\hline
\end{tabular}

Table 4. Evaluation of main banks and status of utilization of new financial products

\begin{tabular}{|c|c|c|c|c|c|c|}
\hline & & \multicolumn{5}{|c|}{$\begin{array}{c}\text { Evaluation of main bank } \\
\text { (1: Excellent to 5: Very poor) }\end{array}$} \\
\hline & & 1 & 2 & 3 & 4 & 5 \\
\hline \multirow{5}{*}{ Know your company } & Overall & $28.1 \%$ & $48.7 \%$ & $18.4 \%$ & $3.7 \%$ & $1.2 \%$ \\
\hline & Small-group privately subscribed bonds & $38.8 \%$ & $43.8 \%$ & $15.0 \%$ & $2.5 \%$ & $0.0 \%$ \\
\hline & Loan guarantee scheme by accounts receivable & $19.2 \%$ & $61.5 \%$ & $15.4 \%$ & $3.8 \%$ & $0.0 \%$ \\
\hline & CLO & $17.6 \%$ & $65.9 \%$ & $14.3 \%$ & $1.1 \%$ & $1.1 \%$ \\
\hline & Quick loans & $19.5 \%$ & $58.5 \%$ & $17.1 \%$ & $2.4 \%$ & $2.4 \%$ \\
\hline \multirow{5}{*}{ Stable provision of funds } & Overall & $26.2 \%$ & $43.6 \%$ & $23.2 \%$ & $4.4 \%$ & $2.5 \%$ \\
\hline & Small-group privately subscribed bonds & $31.3 \%$ & $45.0 \%$ & $21.3 \%$ & $1.3 \%$ & $1.3 \%$ \\
\hline & Loan guarantee scheme by accounts receivable & $30.8 \%$ & $46.2 \%$ & $15.4 \%$ & $0.0 \%$ & $7.7 \%$ \\
\hline & $\mathrm{CLO}$ & $31.9 \%$ & $53.8 \%$ & $12.1 \%$ & $1.1 \%$ & $1.1 \%$ \\
\hline & Quick loans & $14.6 \%$ & $58.5 \%$ & $14.6 \%$ & $7.3 \%$ & $4.9 \%$ \\
\hline \multirow{5}{*}{ Provision of funds at a low interest rate } & Overall & $10.7 \%$ & $38.0 \%$ & $36.7 \%$ & $10.8 \%$ & $3.9 \%$ \\
\hline & Small-group privately subscribed bonds & $10.0 \%$ & $45.0 \%$ & $30.0 \%$ & $12.5 \%$ & $2.5 \%$ \\
\hline & Loan guarantee scheme by accounts receivable & $7.7 \%$ & $50.0 \%$ & $26.9 \%$ & $11.5 \%$ & $3.8 \%$ \\
\hline & CLO & $13.2 \%$ & $39.6 \%$ & $39.6 \%$ & $6.6 \%$ & $1.1 \%$ \\
\hline & Quick loans & $4.9 \%$ & $31.7 \%$ & $43.9 \%$ & $17.1 \%$ & $2.4 \%$ \\
\hline
\end{tabular}


Procurement utilizing Accounts Receivable, the larger the size, the higher is the rate in the four groups having up to 40 employees, but no clear trend is seen in other size groups. What is clearly found is that those with employee sizes 1 and 2 (that is, companies with 22 or fewer employees) have a lower utilization rate of Procurement utilizing Accounts Receivable compared to other size companies. Conversely, according to responses to question asking about difficulties in fund procurement during the past year (Question 10), small businesses responded more frequently that "procurement is difficult"4. Therefore, the diversification of fund procurement has not significantly disseminated among small businesses, despite the fact that they suffer more from fund procurement difficulties. This trend is also seen in the pretax profit status. Namely, while $9.2 \%$ of the companies with two consecutive business years in the red utilized Procurement utilizing Accounts Receivable, $14.7 \%$ of the companies with two consecutive business years in the black utilized this method. The same applies to privately subscribed bonds; specifically, while the utilization rate for companies with two consecutive business years in the red was $2.8 \%$, companies with two consecutive business years in the black showed a rate of $9.8 \%{ }^{5}$. This indicates that the diversification of fund procurement is popular in well-run companies with comfortable fund management.

\subsection{Roles of Main Banks in the Utilization of New Financial Products}

We ask the roles of main banks as the trigger for deciding to use new financial products of "(1) small-group privately subscribed bonds," "(2) loan guarantee scheme by accounts receivable," “(3) CLO,” and “(4) Quick loan," for the past 3 years. Increased dissemination of these products has been supported by policies for facilitating finance for small and medium-sized businesses. In the RIETI questionnaires, the "small-group privately subscribed bonds" is defined as corporate bonds that solicit undertaking subject to less than 50 private individuals (those who have a relationship with the company, such as executives, employees, and clients), the "loan guarantee scheme by accounts receivable" as the scheme

\footnotetext{
${ }^{4}$ For example, while the rate for "difficult" in employee size 1 is $39.7 \%$ and $29.6 \%$ in employee size 2 , the largest companies showed a rate of only $9.4 \%$, which indicates an overall average value of $22.5 \%$.

${ }^{5}$ Clearly, this does not mean that firms with two consecutive business years in the red have leeway for funding. According to the results of questions regarding funding difficulties, while $61.6 \%$ of the companies with two consecutive business years in the red responded, "difficult," $14.9 \%$ of the companies with two consecutive business years in the black responded similarly.

${ }^{6}$ The number of instances of introduction is larger than the number of instances of utilization in the "(2) loan guarantee scheme by accounts receivable." It is possible that there may have been false responses. However, as the question was asking "in the last 3 years" for utilization it is believed that companies that utilized earlier than that period responded as such.
}

that Credit Guarantee Corporation guarantees when borrowing from financial institutions is made, by having accounts receivable as collateral, the "CLO" as the fund procurement from the financial market by selling securities backed by loans to investors, and the "quick loan" as the product in which financial institutions quickly determine whether to finance or not by using the credit scoring model, etc.

While the result is summarized in Table 2, in the case of "(1) small-group privately subscribed bonds," about $90 \%$ of those (85 companies) that had used within the previous 3 years responded that "the trigger of use was an introduction by a main bank." In sum, many were triggered basically by the introduction from main banks for any new financial product, although the introduction rate was slightly lower in the case of a quick $\operatorname{loan}^{6}$. This indicates that it is difficult for small and medium-sized businesses that have poor financial information or knowledge to consider adoption of new financial methods by themselves, and the roles of financial institutions are significantly larger.

Figure 2 shows the utilization rates calculated by the same employee size classification as Figure 1 for these four financial products. By looking at this figure, in the case of small-group privately subscribed bonds, the utilization rate is higher in the group of companies with employee sizes 6 to 8 , and almost no utilization is implemented in the smallest size groups. CLO has the same tendency as the small-group privately subscribed bonds. On the other hand, the loan guarantee scheme based on accounts receivable shows an exceptionally high rate in the largest size group, but other than that, the utilization rate is clearly quite high in the smaller employee size groups. However, the rate remains at about $2 \%$ at the highest. The same can be said for quick loans, showing a higher utilization rate in smaller employee size groups. Furthermore, although it is not shown in a figure or table, when the status of utilization of these four financial methods in the current earnings situation was investigated, companies with poor performance utilized the loan guarantee scheme by accounts receivable or quick loans, while companies with good performance often utilized small-group privately subscribed bonds or CLO.

\subsection{Relationship between Diversification of Fund Procurement and Main Banks}

Next, the utilization rate by main banks categories regarding the four financing methods analyzed in Table 2 was investigated. As a result (Table 3), with regard to privately subscribed bonds and CLO, the utilization rate was high among companies for which the main banks were city banks, and conversely, concerning the loan guarantee scheme based on accounts receivable or quick loans, the utilization rate was higher among the firms for which the main banks were regional banks or credit as- 
sociations (or Shinkin Bank).

It is possible that this may simply reflect differences by type of operation of average sized companies that are used as main banks. To control this size factor, Table 3 also shows the figures by companies with 22 or fewer employees and those with 23 to 40 employees. This shows that companies for which the main banks were city banks utilized privately subscribed bonds or CLO more than those for which the main banks were regional banks or credit associations, even within the same employee size group. This indicates that not only the corporate situations but also the enthusiasm or capabilities of financial institutions affect the diversification of fund procurement.

The rate of satisfaction with current main banks was also asked in our survey questionnaires (Question 35). The relationship between the evaluation of current main banks and the use/non-use of four financial methods was investigated according to the three items of "know your company," "provision of funds at a low interest rate," and "stable provision of funds" among them.

The results are summarized in Table 4. First, from the perspective of "know your company," companies that utilized privately subscribed bonds gave a high rating to the main banks. Conversely, the evaluation of the main banks was relatively poor among companies that utilized quick loans. It is understandable in the case of quick loans, because the element of "knowing your clients" is not as necessary as in relationship banking due to the loan scoring method. However, as approximately $80 \%$ was introduced by a main bank according to the previous response, the companies were dissatisfied, assuming that they were asked to utilize quick loans because the main bank did not know them well. Alternatively, it appears as though some companies have no other choice but to use the quick loans of other banks, as the main bank does not respond well enough.

On the other hand, it is interesting that companies utilizing privately subscribed bonds gave high ratings for main banks, stating that the bank knew them well. "Knowing your company" is the basis of relationship banking, and it is well known that this is essential in lending for small and medium-sized businesses. However, companies that have close relationships with banks implement non-loan fund procurement, utilizing the security market such as with privately subscribed bonds. The possibility that the relationship with clients may have

\footnotetext{
${ }^{7}$ Question 45 asked whether the main bank has strengthened "the depth of knowledge of your company itself" in the past 2 years. The rate at which "strengthened" was selected among companies utilizing privately subscribed bonds was $15.7 \%$, while that among companies utilizing quick loans was $23.8 \%$, which indicates that "strengthened" was not necessarily selected more frequently among companies utilizing privately subscribed bonds. In other words, it can be interpreted that the results of Table 5 indicate that privately subscribed bonds were issued to companies that were basically "well known."
}

strengthened during the process of issuing privately subscribed bonds cannot be denied, judging from other questions in these questionnaires ${ }^{7}$. Therefore, this result reflects that there is almost no second market for privately subscribed bonds at present but they are rather simply a replacement for bank lending. This indicates that the issuance of privately subscribed bonds has a severe limitation as a financing method for small and medium-sized businesses which have financial difficulties.

With regard to the "stable provision of funds," companies that utilize privately subscribed bonds, the creditguarantee system based on accounts receivable and CLO, gave high ratings for main banks. This seems an unexpected result, because companies that receive unstable fund provision from main banks must have a stronger need for such new financial products. However, it is possible that the evaluation of "stable provision of funds" has been improved due to such methods, by considering that new financial products are a part of the lending capabilities of main banks. According to the results of the questionnaire in this study, the latter situation may be the case.

Currently, excellent clients use them in the process of further improvement of fund procurement, and we are not in a situation in which they are helpful in fund procurement for companies that have difficulties borrowing funds from the main banks. On the other hand, companies that utilize quick loans give a poor rating for the main banks. It is believed that they feel as though they have no other choice but to use quick loans because of the unstable provision of funds from the main banks.

The last aspect of "provision of funds at a low interest rate" showed a similar tendency as has been mentioned above, and companies utilizing quick loans particularly gave poor ratings.

\section{Conclusions}

In this paper, the current status of diversification of fund procurement for small and medium-sized businesses in Japan was analyzed based on a survey questionnaire that the RIETI implemented in 2005. According to the questionnaire, many companies responded that the trigger for utilizing new financial products was an introduction by a main bank, and I was able to verify that fund procurement methods for small and medium-sized businesses have diversified as a result of efforts made by the policy-making authorities and financial institutions. However, the utilization rate of each financing method remained at a few percentage points, and diversification has not significantly improved small businesses as a whole and, particularly, those that have financing difficulties. Furthermore, although in relative terms, the quick loan method is being utilized by small businesses with poor performance, this does not mean that diversification has improved financial environments of small firms, but rather that it appears to be a result of the fact that strong 
relationship with banks has become unavailable to firms with poor performance.

On the other hand, companies that utilize privately subscribed bonds or CLO likely rate the main banks very highly from the viewpoint that they "know our company very well" and they think that they keep good relationships with the main banks. Although some improvement of the situation of small and medium-sized businesses with financing difficulties had been realized, current increased diversification has found mainly among excellent small and medium-sized businesses with strong financial conditions. Therefore, we are not at a stage in which the utilization of new financial products contributes considerably to improvement of the financial environment of small and medium-sized businesses as a whole. Furthermore, the results of the questionnaire indicate that privately subscribed bonds are simply a modified form of bank lending at the moment, and it can be said that we are not at a stage in which the issuance of privately subscribed bonds significantly contributes to the construction of a multi-stream financial system.

Finally, although the number of dealings with new financial products by private financial institutions has been steadily increasing, further efforts must be made to facilitate the diversification of fund procurement for small and medium-sized businesses amidst severe conditions.

\section{REFERENCES}

[1] Yamori, N., 2006, "Financial services that corporations want and challenges of financing for small and medium-sized businesses: Focusing on corporate awareness survey concerning corporate finance in the Kansai Region (in Japanese),” RIETI Discussion Paper 06-J-003.

[2] Yamori, N., 2007, "Japanese corporate finance: What factors affect the financial decisions of Japanese firms?” Alan N. Kendall, ed., International Business and Finance Issues, Nova Science Publishers, Inc., pp. 81-102.

[3] Uchida, H., Udell, G. F., and Yamori, N., "Loan officers and relationship lending,” RIETI Discussion Paper Series 06-E-031, June 2006.

[4] Uchida, H., Udell, G. F., and Yamori, N., "How do Japanese banks discipline small and medium-sized borrowers?: An investigation of the deployment of lending technologies," International Finance Review (Institutional approach to global corporate governance), Vol. 9, pp. 5780, 2008. 